\title{
Oleanolic Triterpene Saponins from the Roots of Panax bipinnatifidus
}

\author{
Nguyen Huu Tung,,${ }^{a, b}$ Tran Hong Quang, ${ }^{a, b}$ Nguyen Thi Thanh NGAN, ${ }^{a}$ Chau Van Minh, ${ }^{b}$ \\ Bui Kim AnH, ${ }^{c}$ Pham Quoc Long, ${ }^{d}$ Nguyen Manh Cuong, ${ }^{d}$ and Young Ho KIM*,a \\ ${ }^{a}$ College of Pharmacy, Chungnam National University; Daejeon 305-764, Korea: ${ }^{b}$ Institute of Marine Biochemistry, \\ Vietnam Academy of Science and Technology; ' Institute of Chemistry, Vietnam Academy of Science and Technology; and \\ ${ }^{d}$ Institute of Natural Products Chemistry, Vietnam Academy of Science and Technology; 18 Hoang Quoc Viet, Caugiay, \\ Hanoi, Vietnam. Received June 16, 2011; accepted August 1, 2011; published online August 5, 2011
}

Ten oleanane-type saponins $(1-10)$, including three new compounds, namely bifinosides $\mathrm{A}-\mathrm{C}(1-3)$, were isolated from the roots of Panax bipinnatifidus SEEM. Their structures were elucidated on the basis of chemical and spectroscopic methods.

Key words Panax bipinnatifidus; Araliaceae; oleanane triterpene; oleanolic acid; bifinoside

Panax bipinnatifidus SEem. (Araliaceae) is a hygrophilous and shade-enduring plant, preferring cool and wet climate conditions with an average temperature of about $12-15^{\circ} \mathrm{C}$. In nature, this plant is relatively rare and mostly found in the high mountainous region of Hoang Lien Son in the northwest of Vietnam. The root of P. bipinnatifidus has been used as a valuable tonic to increase mental and physical performance, improve thinking and memory, reduce cancer risk, and lower blood sugar in diabetics in the Vietnamese traditional medicine. ${ }^{1)}$ To date, phytochemical studies on this plant have been not undertaken extensively. In our ongoing research on Panax plants, the presence of saponins in polar fractions of a methanol extract of this plant was suggested. From other plants of the same genus such as $P$. ginseng and P. stipuleanatus, many kinds of saponins have been identified. ${ }^{2-5)}$ We therefore carried out a study of saponins of the title plant. This paper herein deals with the isolation and structural identification of ten saponins $(\mathbf{1}-\mathbf{1 0})$ from the root of P. bipinnatifidus.

\section{Results and Discussion}

The methanolic extract from the roots of P. bipinnatifidus was suspended in water and partitioned with $\mathrm{CH}_{2} \mathrm{Cl}_{2}$. The $\mathrm{H}_{2} \mathrm{O}$ layer was subjected to Diaion HP-20 column chromatography, followed by various silica gel and C-18 reversed-phase columns to afford three new saponins, bifinosides $\mathrm{A}-\mathrm{C}(\mathbf{1}-\mathbf{3})$, and seven known compounds including narcissiflorine methyl ester (4), ${ }^{6}$ chikusetsusaponin IVa (5), ${ }^{5}$ pseudoginsenoside $\mathrm{RP}_{1}$ methyl ester $(\mathbf{6}),{ }^{5}$ ) stipuleanoside $\mathrm{R}_{1}$ $(7),{ }^{7}$ pseudoginsenoside $\mathrm{RT}_{1}$ methyl ester $(\mathbf{8}),{ }^{5}$ momordin IIe (9), ${ }^{8)}$ and stipuleanoside $\mathrm{R}_{2}$ methyl ester $(\mathbf{1 0}){ }^{5)}$ respectively (Fig. 1).

Bifinoside A (1), a white amorphous powder, has the molecular formula $\mathrm{C}_{42} \mathrm{H}_{66} \mathrm{O}_{13}$ as determined by high resolusionelectrospray ionization-time-of-flight-mass spectrometry (HR-ESI-TOF-MS) experiment (Found at $\mathrm{m} / \mathrm{z}[\mathrm{M}+\mathrm{H}]^{+}$ 779.4596, Calcd for $\mathrm{C}_{42} \mathrm{H}_{67} \mathrm{O}_{13}$ 779.4582). Acid hydrolysis of 1 liberated oleanolic acid and sugar components of D-glucuronic acid and L-arabinose as confirmed by gas chromatography (GC) analysis. The ${ }^{1} \mathrm{H}-\mathrm{NMR}$ spectrum of the aglycon moiety of 1 showed seven tertiary methyl groups at $\delta 0.75$, $0.78,0.86,0.88,0.89,0.98$, and 1.10 , that correlated in the heteronuclear multiple quantum coherence (HMQC) experiments with the carbon signals at $\delta 17.7,15.9,33.6,24.0$, $16.5,28.2$, and 26.4, respectively (Tables $1-3$ ). A further
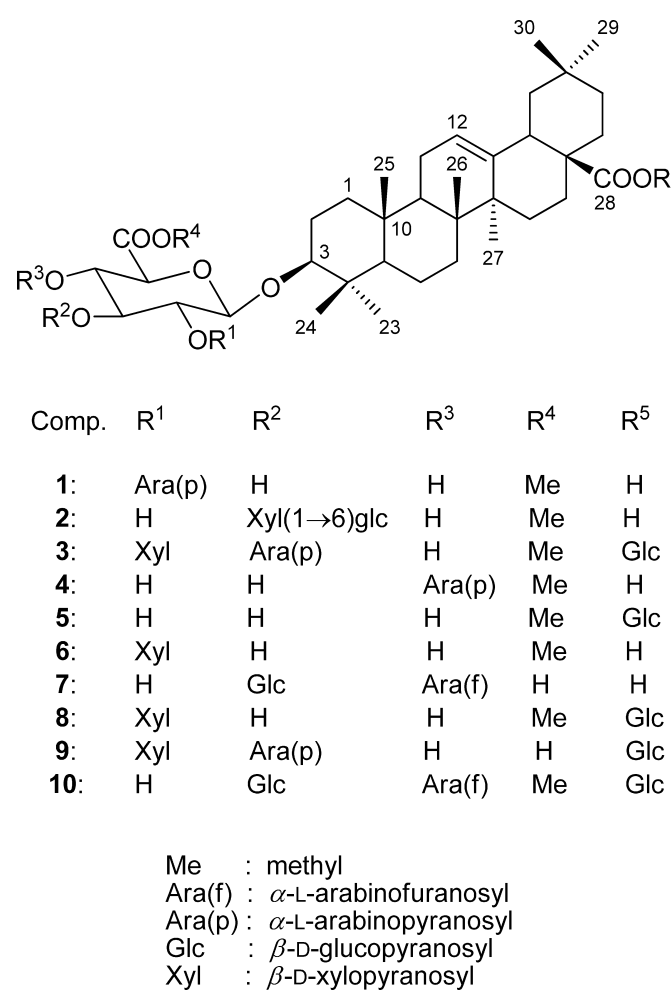

Fig. 1. Structures of Saponins $\mathbf{1}-\mathbf{1 0}$

feature was the signal at $\delta 5.16(1 \mathrm{H}, \mathrm{t}, J=5.4 \mathrm{~Hz})$, typical of $\mathrm{H}-12$ of $\Delta^{12}$ oleanene skeleton, which was further confirmed by the presence of the signals at $\delta 123.7(\mathrm{C}-12)$ and 145.2 (C-13) in the ${ }^{13} \mathrm{C}$-NMR spectrum. ${ }^{7,9)} \mathrm{A}$ signal at $\delta 181.9$ and the carbon resonances of ring $\mathrm{D}$ in the ${ }^{13} \mathrm{C}-\mathrm{NMR}$ spectrum similar to those of oleanolic acid suggested the occurrence of a free carboxylic group at the C-28 position. Furthermore, the glycosylated $3 \beta$-hydroxy oleanolic acid was proposed as the presence of a secondary alcoholic function from the signal at $\delta 3.07(1 \mathrm{H}, \mathrm{dd}, J=11.4,4.2 \mathrm{~Hz})$, which correlated in the HMQC spectrum with the downfield carbon signal at $\delta$ 91.3.

The ${ }^{1} \mathrm{H}$ - and ${ }^{13} \mathrm{C}-\mathrm{NMR}$ spectra of $\mathbf{1}$ showed the presence of two anomeric protons at $\delta 4.36(\mathrm{~d}, J=5.2 \mathrm{~Hz})$ and $4.44(\mathrm{~d}$, $J=7.8 \mathrm{~Hz}$ ) and carbons at $\delta 105.6$ and 106.3 . Additionally, the appearance of a methoxy proton at $\delta 3.70(3 \mathrm{H}, \mathrm{s})$, which correlated with the carbon signal at $\delta 52.8$ in the HMQC spectrum and with the carbon resonance at $\delta 171.2$ in the 
Table 1. ${ }^{13} \mathrm{C}-\mathrm{NMR}$ Data $\left(\boldsymbol{\delta}, \mathrm{CD}_{3} \mathrm{OD}\right)$ for Bifinosides $\mathrm{A}-\mathrm{C}(\mathbf{1}-\mathbf{3})$

\begin{tabular}{|c|c|c|c|c|c|c|c|}
\hline Carbon & 1 & 2 & 3 & Carbon & 1 & 2 & 3 \\
\hline Aglycone & & & & Sugar moiety & 3-GluAMe (I) & 3-GluAMe (I) & 3-GluAMe (I) \\
\hline 1 & 39.8 & 39.8 & 39.9 & 1 & 105.6 & 105.8 & 105.8 \\
\hline 2 & 27.1 & 27.1 & 27.1 & 2 & 82.7 & 74.7 & 79.6 \\
\hline 3 & 91.3 & 91.9 & 91.8 & 3 & 77.6 & 86.5 & 86.5 \\
\hline 4 & 40.3 & 40.4 & 40.7 & 4 & 71.2 & 70.0 & 71.6 \\
\hline 5 & 57.1 & 57.1 & 57.1 & 5 & 77.8 & 77.9 & 76.1 \\
\hline 6 & 19.3 & 19.3 & 19.3 & 6 & 171.2 & 171.0 & 170.9 \\
\hline 7 & 33.8 & 33.8 & 33.1 & $\mathrm{COOCH}_{3}$ & 52.8 & 52.9 & 52.9 \\
\hline 8 & 40.6 & 40.6 & 40.4 & & $\operatorname{Ara}(\mathrm{p})(\mathrm{II})$ & Glc (II) & Xyl (II) \\
\hline 9 & 48.8 & 48.8 & 49.8 & 1 & 106.3 & 105.0 & 104.5 \\
\hline 10 & 37.9 & 37.9 & 37.9 & 2 & 72.9 & 74.7 & 76.1 \\
\hline 11 & 24.5 & 24.5 & 24.6 & 3 & 74.8 & 78.3 & 78.2 \\
\hline 12 & 123.7 & 123.6 & 123.8 & 4 & 67.2 & 71.6 & 71.1 \\
\hline 13 & 145.2 & 145.2 & 144.8 & 5 & 64.3 & 79.6 & 66.9 \\
\hline 14 & 42.9 & 42.9 & 42.9 & 6 & & 67.9 & \\
\hline 15 & 28.9 & 28.9 & 28.9 & & & Xyl (III) & $\operatorname{Ara}(\mathrm{p})(\mathrm{III})$ \\
\hline 16 & 24.1 & 24.1 & 24.0 & 1 & & 104.5 & 104.9 \\
\hline 17 & 47.7 & 47.7 & 48.0 & 2 & & 76.1 & 72.9 \\
\hline 18 & 42.8 & 42.8 & 42.6 & 3 & & 78.1 & 74.6 \\
\hline 19 & 47.3 & 47.3 & 47.2 & 4 & & 71.5 & 67.9 \\
\hline 20 & 31.6 & 31.6 & 31.4 & 5 & & 66.9 & 64.9 \\
\hline 21 & 34.9 & 34.9 & 34.1 & & & & 28-Glc (IV) \\
\hline 22 & 34.0 & 34.0 & 33.1 & 1 & & & 95.6 \\
\hline 23 & 28.2 & 28.2 & 28.3 & 2 & & & 73.9 \\
\hline 24 & 16.5 & 16.6 & 16.0 & 3 & & & 78.6 \\
\hline 25 & 15.9 & 16.0 & 16.6 & 4 & & & 71.4 \\
\hline 26 & 17.7 & 17.7 & 17.7 & 5 & & & 78.2 \\
\hline 27 & 26.4 & 26.4 & 26.5 & 6 & & & 62.4 \\
\hline 28 & 181.9 & 181.9 & 178.0 & & & & \\
\hline 29 & 33.6 & 33.6 & 33.5 & & & & \\
\hline 30 & 24.0 & 24.0 & 23.9 & & & & \\
\hline
\end{tabular}

Table 2. ${ }^{1} \mathrm{H}-\mathrm{NMR}$ Data $\left(\delta, \mathrm{CD}_{3} \mathrm{OD}\right)$ of the Aglycon Moieties of Bifinosides $\mathrm{A}-\mathrm{C}(\mathbf{1}-\mathbf{3})^{a)}$

\begin{tabular}{|c|c|c|c|}
\hline $\mathrm{H}$ & 1 & 2 & 3 \\
\hline 1 & $0.93,1.56,2 \mathrm{H}^{\mathrm{b})}$ & $0.93,1.57,2 \mathrm{H}^{\mathrm{b})}$ & $0.92,1.57,2 \mathrm{H}^{\mathrm{b})}$ \\
\hline 2 & $1.60,1.77,2 \mathrm{H}^{\mathrm{b})}$ & $1.61,1.77,2 \mathrm{H}^{\mathrm{b})}$ & $1.62,1.76,2 \mathrm{H}^{\mathrm{b})}$ \\
\hline $\begin{array}{l}3 \\
4\end{array}$ & $3.07,1 \mathrm{H}, \mathrm{dd}(11.4,4.2)$ & $3.08,1 \mathrm{H}, \mathrm{dd}(11.4,4.2)$ & $3.10,1 \mathrm{H}, \mathrm{dd}(11.4,4.2)$ \\
\hline 5 & $0.78,1 \mathrm{H}, \mathrm{dd}(12.0,4.2)$ & $0.78,1 \mathrm{H}, \mathrm{dd}(12.0,4.2)$ & $0.78,1 \mathrm{H}, \mathrm{dd}(12.0,4.2)$ \\
\hline 6 & $1.36,1.53,2 \mathrm{H}^{\mathrm{b})}$ & $1.36,1.54,2 \mathrm{H}^{\mathrm{b})}$ & $1.36,1.54,2 \mathrm{H}^{\mathrm{b})}$ \\
\hline $\begin{array}{l}7 \\
8\end{array}$ & $1.15,1.26,2 \mathrm{H}^{\mathrm{b})}$ & $1.15,1.26,2 \mathrm{H}^{\mathrm{b})}$ & $1.15,1.26,2 \mathrm{H}^{\mathrm{b})}$ \\
\hline $\begin{array}{r}9 \\
9\end{array}$ & $1.54,1 \mathrm{H}^{\mathrm{b})}$ & $1.54,1 \mathrm{H}^{\mathrm{b})}$ & $1.53,1 \mathrm{H}^{\mathrm{b})}$ \\
\hline 11 & $1.48,1.88,2 \mathrm{H}^{\mathrm{b})}$ & $1.48,1.88,2 \mathrm{H}^{\mathrm{b})}$ & $1.48,1.88,2 \mathrm{H}^{\mathrm{b})}$ \\
\hline 12 & $5.16,1 \mathrm{H}, \mathrm{t}(5.4)$ & $5.17,1 \mathrm{H}, \mathrm{t}(5.4)$ & $5.18,1 \mathrm{H}, \mathrm{t}(5.4)$ \\
\hline 13 & & & \\
\hline 14 & & & \\
\hline 15 & $1.02,1.72,2 \mathrm{H}^{\mathrm{b})}$ & $1.02,1.72,2 \mathrm{H}^{\mathrm{b})}$ & $1.04,1.74,2 \mathrm{H}^{\mathrm{b})}$ \\
\hline 16 & $\left.1.80-1.91,2 \mathrm{H}^{\mathrm{b}}\right)$ & $\left.1.80-1.90,2 \mathrm{H}^{\mathrm{b}}\right)$ & $\left.1.80-1.91,2 \mathrm{H}^{\mathrm{b}}\right)$ \\
\hline 17 & & & \\
\hline 18 & $2.82,1 \mathrm{H}, \mathrm{dd}(12.6,4.2)$ & $2.80,1 \mathrm{H}, \mathrm{dd}(12.6,4.2)$ & $2.82,1 \mathrm{H}, \mathrm{dd}(12.6,4.2)$ \\
\hline 19 & $1.10,1.65,2 \mathrm{H}^{\mathrm{b})}$ & $1.10,1.65,2 \mathrm{H}^{\mathrm{b})}$ & $1.12,1.67,2 \mathrm{H}^{\mathrm{b})}$ \\
\hline 20 & & & \\
\hline 21 & $1.17,1.36,2 \mathrm{H}^{\mathrm{b})}$ & $1.17,1.36,2 \mathrm{H}^{\mathrm{b})}$ & $1.18,1.36,2 \mathrm{H}^{\mathrm{b})}$ \\
\hline 22 & $1.49,1.71,2 \mathrm{H}^{\mathrm{b})}$ & $1.49,1.71,2 \mathrm{H}^{\mathrm{b})}$ & $1.50,1.71,2 \mathrm{H}^{\mathrm{b})}$ \\
\hline 23 & $0.98,3 \mathrm{H}, \mathrm{s}$ & $0.98,3 \mathrm{H}, \mathrm{s}$ & $0.99,3 \mathrm{H}, \mathrm{s}$ \\
\hline 24 & $0.89,3 \mathrm{H}, \mathrm{s}$ & $0.88,3 \mathrm{H}, \mathrm{s}$ & $0.89,3 \mathrm{H}, \mathrm{s}$ \\
\hline 25 & $0.78,3 \mathrm{H}, \mathrm{s}$ & $0.77,3 \mathrm{H}, \mathrm{s}$ & $0.78,3 \mathrm{H}, \mathrm{s}$ \\
\hline 26 & $0.75,3 \mathrm{H}, \mathrm{s}$ & $0.74,3 \mathrm{H}, \mathrm{s}$ & $0.73,3 \mathrm{H}, \mathrm{s}$ \\
\hline 27 & $1.10,3 \mathrm{H}, \mathrm{s}$ & $1.10,3 \mathrm{H}, \mathrm{s}$ & $1.10,3 \mathrm{H}, \mathrm{s}$ \\
\hline 28 & & & \\
\hline 29 & $0.86,3 \mathrm{H}, \mathrm{s}$ & $0.85,3 \mathrm{H}, \mathrm{s}$ & $0.86,3 \mathrm{H}, \mathrm{s}$ \\
\hline 30 & $0.88,3 \mathrm{H}, \mathrm{s}$ & $0.88,3 \mathrm{H}, \mathrm{s}$ & $0.88,3 \mathrm{H}, \mathrm{s}$ \\
\hline
\end{tabular}

a) Assignments were established by HMQC, DQF-COSY, and HMBC spectra. $J$ values (in $\mathrm{Hz}$ ) are given in parentheses. b) Multiplicities not assigned due to overlapped signals.
Table 3. ${ }^{1} \mathrm{H}-\mathrm{NMR}$ Data $\left(\delta, \mathrm{CD}_{3} \mathrm{OD}\right)$ of the Sugar Moieties of Bifinosides $\left.\mathrm{A}-\mathrm{C}(\mathbf{1}-\mathbf{3})^{a}\right)$

\begin{tabular}{|c|c|c|c|}
\hline $\mathrm{H}$ & 1 & 2 & 3 \\
\hline & GluAMe (I) & GluAMe (I) & GluAMe (I) \\
\hline 1 & $4.44,1 \mathrm{H}, \mathrm{d}(7.8)$ & $4.46,1 \mathrm{H}, \mathrm{d}(7.8)$ & $4.46,1 \mathrm{H}, \mathrm{d}(7.2)$ \\
\hline 2 & $3.56,1 \mathrm{H}^{b)}$ & $3.48,1 \mathrm{H}^{b)}$ & $3.64,1 \mathrm{H}, \mathrm{t}(7.8)$ \\
\hline 3 & $3.48,1 \mathrm{H}^{b)}$ & $3.69,1 \mathrm{H}^{b)}$ & $3.71,1 \mathrm{H}^{b)}$ \\
\hline 4 & $3.42,1 \mathrm{H}^{b)}$ & $3.78,1 \mathrm{H}^{b)}$ & $3.58,1 \mathrm{H}^{b)}$ \\
\hline 5 & $3.81,1 \mathrm{H}^{b)}$ & $3.83,1 \mathrm{H}^{b)}$ & $3.85,1 \mathrm{H}^{b)}$ \\
\hline \multicolumn{4}{|l|}{6} \\
\hline \multirow[t]{2}{*}{$\mathrm{COOCH}_{3}$} & $3.70,3 \mathrm{H}, \mathrm{s}$ & $3.70 \mathrm{~s}$ & $3.72,3 \mathrm{H}, \mathrm{s}$ \\
\hline & $\operatorname{Ara}(\mathrm{p})(\mathrm{II})$ & Glc (II) & Xyl (II) \\
\hline 1 & $4.36,1 \mathrm{H}, \mathrm{d}(5.2)$ & $4.70,1 \mathrm{H}, \mathrm{d}(7.8)$ & $4.75,1 \mathrm{H}, \mathrm{d}(7.2)$ \\
\hline 2 & $3.50,1 \mathrm{H}^{b)}$ & $3.26,1 \mathrm{H}^{b)}$ & $3.10,1 \mathrm{H}^{b)}$ \\
\hline 3 & $3.42,1 \mathrm{H}^{b)}$ & $3.30,1 \mathrm{H}^{b)}$ & $3.39,1 \mathrm{H}^{b)}$ \\
\hline 4 & $3.71,1 \mathrm{H}^{b)}$ & $3.34,1 \mathrm{H}^{b)}$ & $3.42,1 \mathrm{H}^{b)}$ \\
\hline 5 & $3.34,3.75,2 \mathrm{H}^{b)}$ & $3.62,1 \mathrm{H}^{b)}$ & $3.60,3.87,2 \mathrm{H}^{b)}$ \\
\hline \multirow[t]{3}{*}{6} & & $3.60,1 \mathrm{H}^{b)}$ & \\
\hline & & $3.85,1 \mathrm{H}, \mathrm{dd}(11.4,5.4)$ & \\
\hline & & Xyl (III) & $\operatorname{Ara}(\mathrm{p})(\mathrm{III})$ \\
\hline 1 & & $4.41,1 \mathrm{H}, \mathrm{d}(7.2)$ & $4.52,1 \mathrm{H}, \mathrm{d}(4.8)$ \\
\hline 2 & & $3.12,1 \mathrm{H}^{b)}$ & $3.56,1 \mathrm{H}^{b)}$ \\
\hline 3 & & $3.24,1 \mathrm{H}^{b)}$ & $3.48,1 \mathrm{H}^{b)}$ \\
\hline 4 & & $3.40,1 \mathrm{H}^{b)}$ & $3.78,1 \mathrm{H}^{b)}$ \\
\hline \multirow[t]{2}{*}{5} & & $3.13,3.72,2 \mathrm{H}^{b)}$ & $3.12,3.75,2 \mathrm{H}^{b)}$ \\
\hline & & & Glc (IV) \\
\hline 1 & & & $5.34,1 \mathrm{H}, \mathrm{d}(7.8)$ \\
\hline 2 & & & $3.29,1 \mathrm{H}^{b)}$ \\
\hline 3 & & & $3.32,1 \mathrm{H}^{b)}$ \\
\hline 4 & & & $3.40,1 \mathrm{H}^{b)}$ \\
\hline 5 & & & $3.42,1 \mathrm{H}^{b)}$ \\
\hline \multirow[t]{2}{*}{6} & & & $3.63,1 \mathrm{H}^{b)}$ \\
\hline & & & $3.80,1 \mathrm{H}, \mathrm{d}(12.0,5.4)$ \\
\hline
\end{tabular}

a) Assignments were established by HMQC, DQF-COSY, and HMBC spectra. $J$ values (in $\mathrm{Hz}$ ) are given in parentheses. b) Multiplicities not assigned due to overlapped signals. 
heteronuclear multiple bond correlation (HMBC) spectrum, suggested the presence of glucuronate methyl ester (Glu$\mathrm{AMe}$ ) moiety. Complete assignments of all the proton resonances in each sugar unit were achieved by double-quantum filtered correlation spectroscopy (DQF-COSY), HMQC, and HMBC spectra (Tables $1-3$ ). In the HMBC experiment, the anomeric signal at $\delta 4.44\left(\mathrm{H}-1_{\mathrm{GluAMe}(\mathrm{I})}\right)$ showed a long-range correlation with the signal at $\delta 91.3(\mathrm{C}-3)$, indicating that glucuronyl moiety is directly linked to the triterpene structure at C-3. Subsequently, the arabinose unit linked to the GluAMe segment was at $\mathrm{H}-2_{\text {GluAMe(I) }}$ on the basis of the $\mathrm{HMBC}$ spectrum, in which the two anomeric protons at $\delta$ $4.36\left(\mathrm{H}-1_{\mathrm{Ara}(\mathrm{II})}\right)$ and $4.44\left(\mathrm{H}-1_{\mathrm{GluAMe}(\mathrm{I})}\right)$ correlated with the same carbon $\mathrm{C}-2_{\mathrm{GluAMe}(\mathrm{I})}$ at $\delta 82.7$. Consequently, bifinoside A (1) was characterized as oleanolic acid 3- $O-\alpha$-L-arabinopyranosyl $(1 \rightarrow 2)$ - $\beta$-D-glucuronopyranoside-6- $O$-methyl ester.

Bifinoside B (2), also a white amorphous power, revealed a quasi-molecular ion peak $[\mathrm{M}+\mathrm{Na}]^{+}$at $m / z 963.4913$ in its HR-ESI-TOF-MS spectrum. Acid hydrolysis of $\mathbf{2}$ afforded oleanolic acid and sugar components of D-glucuronic acid, Dglucose, and D-xylose. The ${ }^{1} \mathrm{H}$ - and ${ }^{13} \mathrm{C}$-NMR spectra showed the presence of oleanolic acid, the same aglycon moiety as saponin 1, which was glycosylated at C-3 as the downfield shift at $\delta 91.9$, and the occurrence of three anomeric signals $\left[\delta_{\mathrm{H}} 4.41_{\mathrm{Xyl}(\mathrm{III})}(\mathrm{d}, J=7.2 \mathrm{~Hz}), 4.70_{\mathrm{Glc}(\mathrm{II})}(\mathrm{d}, J=7.8 \mathrm{~Hz}), 4.46_{\mathrm{GluAMe}(\mathrm{I})}\right.$ (d, $J=7.8 \mathrm{~Hz}$ ), and $\delta_{\mathrm{C}} 104.5,105.0,105.8$, respectively]. The sugar sequence was proposed by HMBC spectrum after assignments of the protons and the carbons by a combination of HMQC and COSY data, starting from the anomeric proton of each sugar unit (Tables 1-3). Accordingly, $\mathrm{H}$ $1_{\text {GluAMe(I) }}(\delta 4.46)$ gave a correlation with the C-3 at $\delta$ 91.9, and a cross peak between $\mathrm{H}-1_{\mathrm{Glc}(\mathrm{II})}(\delta 4.70)$ and $\mathrm{C}-3_{\mathrm{GluAMe}(\mathrm{I})}$ ( $\delta$ 86.5) was revealed. Additionally, a cross peak between $\mathrm{H}-1_{\mathrm{Xyl}(\mathrm{III})}\left(\delta\right.$ 4.41) and C-6 ${ }_{\mathrm{Glc}(\mathrm{II})}(\delta$ 67.9) was also observed. Hence, bifinoside B (2) was concluded to be oleanolic acid 3 - $O$-[ $\beta$-D-xylopyranosyl( $1 \rightarrow 6)$ - $\beta$-D-glucopyranosyl] $(1 \rightarrow 3)$ $\beta$-D-glucuronopyranoside-6- $O$-methyl ester.

Bifinoside C (3), again a white amorphous power, showed a quasi-molecular ion peak $[\mathrm{M}+\mathrm{H}]^{+}$at $m / z 1073.5554$ in the HR-ESI-TOF-MS spectrum. The acid hydrolysis of this saponin liberated oleanolic acid and sugar components of Dglucuronic acid, L-arabinose, D-glucose, and D-xylose based on results of the GC analysis. Four anomeric signals were observed in the ${ }^{13} \mathrm{C}-\mathrm{NMR}$ spectrum at $\delta 95.6,104.5,104.9$, and 105.8 and at $\delta 4.46(1 \mathrm{H}, \mathrm{d}, J=7.2 \mathrm{~Hz}), 4.52(1 \mathrm{H}, \mathrm{d}$, $J=4.8 \mathrm{~Hz}), 4.75(1 \mathrm{H}, \mathrm{d}, J=7.2 \mathrm{~Hz})$, and $5.34(1 \mathrm{H}, J=7.8 \mathrm{~Hz})$ in the ${ }^{1} \mathrm{H}$-NMR spectrum. Furthermore, DQF-COSY and HMQC experiments allowed the sequential assignments of resonances for each sugar, starting from the anomeric proton signals (Tables $1-3$ ). On the other hand, the HMBC spectrum showed the presence of a sugar chain at the C-3 and a monosaccharide unit at the $\mathrm{C}-28$. The sequence of the monosaccharide chain at C-3 was further also defined by the $\mathrm{HMBC}$ spectrum, in which cross peaks of $\mathrm{H}-1_{\text {GluAme(I) }}(\delta$ $4.46) / \mathrm{C}-3\left(\delta\right.$ 91.8), H-1 ${ }_{\mathrm{Xyl}(\mathrm{II})}(\delta 4.75) / \mathrm{C}-2_{\mathrm{GluAMe}(\mathrm{I})}(\delta 79.6)$, and $\mathrm{H}-1_{\mathrm{Ara}(\mathrm{III})}(\delta 4.52) / \mathrm{C}-3_{\mathrm{GluAMe}(\mathrm{I})}(\delta$ 86.5) were observed; and the $\mathrm{C}-28$ position of the triterpene aglycone was glycosylated with the D-glucopyranosyl upon the HMBC correlation of $\mathrm{H}-1_{\mathrm{Glc}(\mathrm{IV})}(\delta 5.34) / \mathrm{C}-28(\delta$ 178.0). On the basis of these findings, bifinoside $\mathrm{C}$ (3) was identified as $28-O-\beta$-D-glu- copyranosyloleanolic acid 3- $O$ - $\beta$-D-xylopyranosyl $(1 \rightarrow 2)$ - $[\alpha-$ L-arabinopyranosyl $(1 \rightarrow 3)]$ - $\beta$-D-glucuronopyranoside-6- $O$ methyl ester.

To the best of our knowledge, there has very limited report on chemical constituents of $P$. bipinnatifidus. The current study has taken well part in research of phytochemical components of the title plant, which is rich in various oleananetype saponins. In the view of Panax genus, $P$. ginseng (Asian ginseng), $P$. quinquefolium (American ginseng), and $P$. vietnamensis among the most used medicinal plants have been well documented with majority of dammarane-type glycosides. ${ }^{10-14)}$ Besides, the other species, P. stipuleanatus was dominated by oleanane-type saponins. ${ }^{5)}$ This result can have a significant chemotaxonomical meaning in the further studies for classification of the Panax species.

\section{Experimental}

General Procedures Optical rotations were obtained using a DIP-360 digital polarimeter (Jasco, Easton, U.S.A.). IR spectra were measured using a Perkin-Elmer 577 spectrometer (Perkin Elmer, Waltham, U.S.A.). NMR spectra were recorded on Bruker DRX 600 NMR spectrometers (Bruker, Billerica, U.S.A.). HR-ESI-TOFMS experiments utilized a JEOL AccuT$\mathrm{OF}^{\mathrm{TM}}$ LC mass spectrometer (Jeol, Tokyo, Japan). GC (Shimadzu-2010, Kyoto, Japan) using a DB-05 capillary column $(0.5 \mathrm{~mm}$ i.d. $\times 30 \mathrm{~m})$ [column temperature, $210^{\circ} \mathrm{C}$; detector temperature, $300^{\circ} \mathrm{C}$; injector temperature, $270^{\circ} \mathrm{C}$; He gas flow rate, $30 \mathrm{ml} / \mathrm{min}$ (splitting ratio: 1/20)] was used for sugar determination. Column chromatography $(\mathrm{CC})$ was performed on silica gel (70-230, 230 - 400 mesh, Darmstadt, Germany), YMC RP-18 resins (30-50 $\mu \mathrm{m}$, Fuji Silysia Chemical Ltd., Aichi, Japan), and HP-20 Diaion (Mitshubishi Chemical, Tokyo, Japan). TLC was performed on Kieselgel 60 $\mathrm{F}_{254}$ (1.05715; Merck) or RP-18 $\mathrm{F}_{254 \mathrm{~s}}$ (Merck) plates. Spots were visualized by spraying with $10 \%$ aqueous $\mathrm{H}_{2} \mathrm{SO}_{4}$ solution, followed by heating.

Plant Material The roots of P. bipinnatifidus were collected in Sapa, Laocai, Vietnam and were taxonomically identified by botanist Ngo Van Trai (Institute of Medicinal Materials, Hanoi, Vietnam). A voucher specimen (VHKC-0370) was deposited at the Herbarium of INPC, Vietnam.

Extraction and Isolation The air-dried roots of $P$. bipinnatifidus $(0.5 \mathrm{~kg})$ were extracted in $\mathrm{MeOH}$, using Soxhlet extraction apparatus $(21$, $12 \mathrm{~h}$ ), and extracts were concentrated in vacuo to dryness. The obtained $\mathrm{MeOH}$ residue $(85 \mathrm{~g})$ was suspended in $\mathrm{H}_{2} \mathrm{O}(0.51)$, then partitioned with $\mathrm{CH}_{2} \mathrm{Cl}_{2}(0.51 \times 3)$ to obtain $\mathrm{CH}_{2} \mathrm{Cl}_{2}$-soluble fraction $(10 \mathrm{~g})$ and the water layer, which was subjected to a Diaion HP-20 column eluted with a gradient of $\mathrm{MeOH}$ in $\mathrm{H}_{2} \mathrm{O}(25,50,75,100 \% \mathrm{MeOH}, \mathrm{v} / \mathrm{v})$ to give four fractions (fr. $1.1-1.4)$. Next, fr. $1.3(23 \mathrm{~g})$ was fractionated on a silica gel column with a gradient of $\mathrm{CH}_{2} \mathrm{Cl}_{2}-\mathrm{MeOH}(10: 1-1: 1)$ to furnish five fractions (fr. 2.1$2.5)$. Fr. $2.1(600 \mathrm{mg})$ was repeatedly chromatographed on a silica gel column with $\mathrm{CHCl}_{3}-\mathrm{MeOH}-\mathrm{H}_{2} \mathrm{O}(6: 1: 0.1)$, followed by reversed-phase columns eluted with $\mathrm{MeOH}-\mathrm{H}_{2} \mathrm{O}(4: 1,5: 1)$ to obtain compounds 1 $(5.4 \mathrm{mg}), \mathbf{4}(3.5 \mathrm{mg}), \mathbf{5}(10.0 \mathrm{mg})$, and $\mathbf{6}(13.0 \mathrm{mg})$, respectively.

Fr. $2.2(2.3 \mathrm{~g})$ and fr. $2.3(2.4 \mathrm{~g})$ were combined due to their similar TLC profiles, and then subjected to a silica gel column with $\mathrm{CHCl}_{3}-\mathrm{MeOH}-\mathrm{H}_{2} \mathrm{O}$ $(4: 1: 0.1)$ to furnish eleven sub-fractions (fr. 3.1-3.11). Next, fr. 3.2 $(140 \mathrm{mg})$ was purified on a RP column with $\mathrm{MeOH}-\mathrm{H}_{2} \mathrm{O}(5: 1)$ to yield compounds $2(15.0 \mathrm{mg})$ and $7(4.5 \mathrm{mg})$. Similarly, fr. $3.4(220 \mathrm{mg})$ was chromatographed over a RP column with $\mathrm{MeOH}-\mathrm{H}_{2} \mathrm{O}(4: 1)$ to yield compound $8(160 \mathrm{mg})$. Fr. $3.7(280 \mathrm{mg})$ was further purified on a RP column with $\mathrm{MeOH}-\mathrm{H}_{2} \mathrm{O}$ to afford compounds 3 (45 mg) and 9 (18 mg). Finally, compound $10(75 \mathrm{mg})$ was obtained from fr. $3.9(250 \mathrm{mg})$ by mean of RP column chromatography with the elution of $\mathrm{MeOH}-\mathrm{H}_{2} \mathrm{O}(4: 1)$.

Bifinoside A (1): White amorphous powder; $[\alpha]_{\mathrm{D}}^{20}+8.0^{\circ}(c=0.4, \mathrm{MeOH})$; IR (KBr): $v_{\max } 3426,2942,1732,1618,1252,1060 \mathrm{~cm}^{-1} ;{ }^{1} \mathrm{H}-\mathrm{NMR}$ $\left(\mathrm{CD}_{3} \mathrm{OD}, 600 \mathrm{MHz}\right)$ and ${ }^{13} \mathrm{C}-\mathrm{NMR}\left(\mathrm{CD}_{3} \mathrm{OD}, 150 \mathrm{MHz}\right)$ : see Tables $1-3$; HR-ESI-TOF-MS: $m / z 779.4596[\mathrm{M}+\mathrm{H}]^{+}\left(\right.$Calcd for $\mathrm{C}_{42} \mathrm{H}_{67} \mathrm{O}_{13}, 779.4582$ ).

Bifinoside B (2): White amorphous powder; $[\alpha]_{\mathrm{D}}^{20}+6.4^{\circ}(c=0.4, \mathrm{MeOH})$; IR (KBr): $v_{\max } 3424,2940,1731,1618,1250,1059 \mathrm{~cm}^{-1} ;{ }^{1} \mathrm{H}-\mathrm{NMR}$ $\left(\mathrm{CD}_{3} \mathrm{OD}, 600 \mathrm{MHz}\right)$ and ${ }^{13} \mathrm{C}-\mathrm{NMR}\left(\mathrm{CD}_{3} \mathrm{OD}, 150 \mathrm{MHz}\right)$ : see Tables $1-3$; HR-ESI-TOF-MS: $m / z \quad 963.4913[\mathrm{M}+\mathrm{Na}]^{+}\left(\mathrm{Calcd}\right.$ for $\mathrm{C}_{48} \mathrm{H}_{76} \mathrm{O}_{18} \mathrm{Na}$, 963.4929).

Bifinoside C (3): White amorphous powder; $[\alpha]_{\mathrm{D}}^{20}+18.6^{\circ}(c=0.7$, $\mathrm{MeOH})$; IR (KBr): $v_{\max } 3428,2946,1718,1624,1248,1054 \mathrm{~cm}^{-1}$; ${ }^{1} \mathrm{H}-\mathrm{NMR}$ $\left(\mathrm{CD}_{3} \mathrm{OD}, 600 \mathrm{MHz}\right)$ and ${ }^{13} \mathrm{C}-\mathrm{NMR}\left(\mathrm{CD}_{3} \mathrm{OD}, 150 \mathrm{MHz}\right)$ : see Tables $1-3$; 
HR-ESI-TOFMS: $m / z$ 1073.5554 [M+H] ${ }^{+}\left(\right.$Calcd for $\left.\mathrm{C}_{53} \mathrm{H}_{85} \mathrm{O}_{22}, 1073.5533\right)$.

Acid Hydrolysis and Sugar Determination of Bifinosides A-C (1-3) A solution of each $(3.0 \mathrm{mg})$ in $2 \mathrm{M} \mathrm{HCl}(5.0 \mathrm{ml})$ was heated under reflux for $4 \mathrm{~h}$. Then, the reaction mixture was concentrated in vacuo to dryness. The residue was extracted with $\mathrm{CH}_{2} \mathrm{Cl}_{2}$ and $\mathrm{H}_{2} \mathrm{O}(5 \mathrm{ml} \times 3)$. The organic portion was concentrated and examined on TLC [Silica gel plates with the mobile phase systems of $\mathrm{CHCl}_{3}$-EtOAc $(7: 1)$ and hexane-acetone $(2: 1)$ comparing with oleanolic acid $(R f 0.52,0.45)]$. Next, the sugar residue, obtained by concentration of the water layer, was examined on TLC [Merck cellulose plate with the mobile phase system of benzene/ $n$-butanol/pyridine/water $(1: 5: 3: 3)]$ and GC (as tetramethylsilane (TMS) ethers according to the reported method). ${ }^{2,4)}$ TLC: $R f 0.22$ (GluA) observed for all three hydrolysates and the others: 0.34 (Ara) for 1; 0.30 (Glc) and 0.38 (Xyl) for 2; 0.30 (Glc), 0.34 (Ara), and 0.38 (Xyl) for $\mathbf{3}$ in comparison with authentic sugars (Sigma-Aldrich). GC: $t_{\mathrm{R}}(\mathrm{min})$ : 4.46 (L-arabinose) for 1; 8.21 (D-xylose) and 14.12 (D-glucose) for $2 ; 4.46$ (L-arabinose), 8.21 (D-xylose), and 14.12 (Dglucose) for 3 , which were in consistent with $t_{\mathrm{R}}$ data of the standard sugars after being treated in the similar manner [ 4.46 (L-arabinose), 4.90 (D-arabinose), 8.21 (D-xylose), 8.66 (L-xylose), 14.12 (D-glucose), 14.25 (L-glucose)].

Acknowledgments This study was supported by Priority Research Centers Program through the National Research Foundation of Korea (NRF) funded by the Ministry of Education, Science and Technology (20090093815), Republic of Korea, and by Vietnam Ministry of Science and Technology (Project 52/2011/HD-NDT). The authors would like to thank the KBSI for NMR measurements.

\section{References}

1) Bich D. H., "Medicinal Plants and Animals in Vietnam," Vol. 2, Sci- ence and Technical Publishing House, Hanoi, 2004, p. 711.

2) Tung N. H., Song G. Y., Park Y. J., Kim Y. H., Chem. Pharm. Bull., 57, 1412-1414 (2009)

3) Tung N. H., Song G. Y., Kim J. A., Hyun J. H., Kang H. K., Kim Y. H., Bioorg. Med. Chem. Lett., 20, 309-314 (2010).

4) Tung N. H., Song G. Y., Minh C. V., Kiem P. V., Jin L. G., Boo H. J., Kang H. K., Kim Y. H., Chem. Pharm. Bull., 58, 1111-1115 (2010).

5) Liang C., Ding Y., Nguyen H. T., Kim J. A., Boo H. J., Kang H. K., Nguyen M. C., Kim Y. H., Bioorg. Med. Chem. Lett., 20, 7110-7115 (2010).

6) Mei H., Kazunori O., Yutaka S., Pei-Gen X., Phytochemistry, 39, 179-184 (1995).

7) Sakai S., Katsumata M., Satoh Y., Nagasao M., Miyakoshi M., Ida Y., Shoji J., Phytochemistry, 35, 1319-1324 (1994).

8) Kawamura N., Watanabe H., Oshiro H., Phytochemistry, 27, 35853591 (1988).

9) Ukiya M., Akihisa T., Yasukawa K., Tokuda H., Suzuki T., Kimura Y., J. Nat. Prod., 69, 1692-1696 (2006).

10) Park J. D., Rhee D. K., Lee Y. H., Phytochem. Rev., 4, 159-175 (2005).

11) Shibata S., J. Korean Med. Sci., 16, 28-37 (2001).

12) Yoshikawa M., Sugimoto S., Nakamura S., Sakumae H., Matsuda H., Chem. Pharm. Bull., 55, 1034-1038 (2007).

13) Yoshikawa M., Sugimoto S., Nakamura S., Matsuda H., Chem. Pharm Bull., 55, 571-576 (2007)

14) Duc N. M., Kasai R., Ohtani K., Ito A., Nham N. T., Yamasaki K., Tanaka O., Chem. Pharm. Bull., 42, 115-122 (1994). 